\title{
Promoting effects of isobavachin on neurogenesis of mouse embryonic stem cells were associated with protein prenylation
}

\author{
Dan-yin WANG ${ }^{1}$, Yu-zhe HU ${ }^{1, \#}$, Si-si KONG ${ }^{1, \#}$, Yong-ping YU², Dan-yan ZHU ${ }^{1, *}$, Yi-jia LOU ${ }^{1, *}$ \\ ${ }^{1}$ Division of Cardio-Cerebral Vascular and Hepatic Pharmacology, College of Pharmaceutical Sciences, Zhejiang University; ${ }^{2}$ Institute of \\ Materia Medica, Zhejiang University, Hangzhou 310058, China
}

\begin{abstract}
Aim: Some small molecules can induce mouse embryonic stem (ES) cells to differentiate into neuronal cells. Here, we explored the effect of isobavachin (IBA), a compound with a prenyl group at position 8 of ring A, on promoting neuronal differentiation and the potential role of its protein prenylation.

Methods: The hanging drop method was employed for embryonic body (EB) formation to mimic embryo development in vivo. The EBs were treated with IBA at a final concentration of $10^{-7} \mathrm{~mol} / \mathrm{L}$ from EB stage (d 4) to d 8+10. Geranylgeranyltransferase I inhibitor GGTI298 was subsequently used to disrupt protein prenylation. Neuronal subtypes, including neurons and astrocytes, were observed by fluorescence microscopy. Gene and protein expression levels were detected using RT-PCR and Western blot analysis, respectively. Results: With IBA treatment, nestin was highly expressed in the neural progenitors generated from EBs (d 4, $d 8+0)$. EBs then further differentiated into neurons (marked by $\beta$-tubulin III) and astrocytes (marked by GFAP), which were both up-regulated in a timedependent manner on $\mathrm{d} 8+5$ and d 8+10. Co-treatment with GGTI-298 selectively abolished the IBA-induced neuronal differentiation. Moreover, in the MAPK pathway, p38 and JNK phosphorylation were down-regulated, while ERK phosphorylation was up-regulated after IBA treatment at different neuronal differentiation passages.
\end{abstract}

Conclusion: IBA can facilitate mouse ES cells differentiating into neuronal cells. The mechanism involved protein prenylation and, subsequently, phos-ERK activation and the phos-p38 off pathway.

Keywords: mouse embryonic stem cells; isobavachin; neurogenesis; protein prenylation; ERK; MAPK; p38

Acta Pharmacologica Sinica (2011) 32: 425-432; doi: 10.1038/aps.2011.5; published online 28 Mar 2011

\section{Introduction}

Embryonic stem (ES) cells are pluripotent cells that have the capacity to continuously proliferate while retaining the potential to differentiate into three germ cells (cells derived from the end-, mes-, and ectoderm).

Mouse ES cells or their derivatives have been widely studied in the field of developmental biology, drug discovery and regenerative medicine ${ }^{[1-3]}$. Small molecules offer distinct advantages for the differentiation of mouse ES cells and are useful tools to facilitate therapeutic applications. Moreover, small molecules can provide temporal control over protein functions, inducing rapid activation or inhibition, and the effects are often reversible and can be adjusted by varying

\footnotetext{
\# Undergraduate students in Research Training Project at Zhejiang University.

* To whom correspondence should be addressed.

E-mail zdyzxb@zju.edu.cn (Dan-yan ZHU); yijialou@zju.edu.cn (Yi-jia LOU)

Received 2010-09-29 Accepted 2011-01-12
}

the concentrations of small molecules ${ }^{[3,4]}$. Furthermore, a single small molecule can simultaneously regulate multiple specific targets within a protein family or across various protein families ${ }^{[5]}$. Small molecules for neuronal differentiation from mouse ES cells have received increasing attention as potential treatments for neurodegenerative diseases, such as Alzheimer's and Parkinson's diseases ${ }^{[6,7]}$. However, there still remains a question about how small molecules direct and control the neuronal differentiation of mouse ES cells ${ }^{[8]}$. Recently, several small molecules have been reported to have neuronal differentiation ability. We have previously demonstrated that prenylflavonid compounds, such as icaritin ${ }^{[9]}$, can promote neuronal differentiation of ES cells in an estrogen receptorindependent manner in vitro ${ }^{[9]}$. However, the structurerelated neuronal differentiation mechanisms are still poorly understood. It is, therefore, important to identify the intrinsic or extrinsic factors that regulate the underlying molecular mechanisms involved in ES cell self-renewal, proliferation and neuronal differentiation ${ }^{[8]}$. Thus, isobavachin (IBA, Figure 1), 


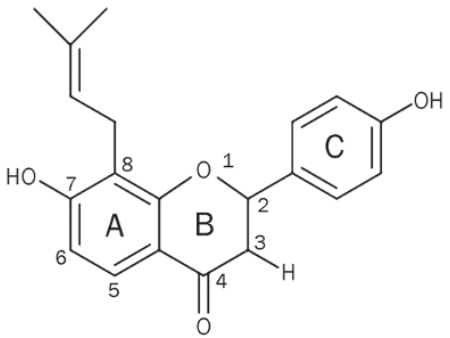

Figure 1. Chemical structure of isobavachin (IBA).

a prenylflavonid compound with a prenyl group at position 8 of ring $\mathrm{A}$, was used to evaluate the possible differentiation effects and potential mechanisms.

Protein prenylation is a process of posttranslational modification present in a great number of proteins ${ }^{[10]}$. It has been proposed to be responsible for membrane association and protein-protein interactions, which contribute to its role in signal transduction pathways ${ }^{[11,12]}$. Geranylgeranyltransferase I (GGTase I) is necessary for protein prenylation and is involved in cell survival, proliferation, and migration ${ }^{[12,13]}$. GGTase I is also associated with the mitogen-activated protein kinase (MAPK) pathway ${ }^{[10]}$. The MAPK pathway regulates cell survival, proliferation, differentiation and motility ${ }^{[14,15]}$, such as the case of differentiation of mouse ES cells ${ }^{[15-17]}$. In the MAPK pathway, sustained activation or phosphorylation of extracellular signal-regulated kinase (ERK) is a specific requirement for the neural lineage commitment ${ }^{[8]}$ and is associated with neuritis formation and neuron survival during ES cells differentiation $^{[16]}$. In addition to ERK, p38MAPK phosphorylation is also activated during early mouse ES cell differentiation ${ }^{[8,15]}$. This was proved to be a trigger in determining the ES cell differentiation fate ${ }^{[15]}$. The control of p38MAPK activity constitutes an early switch in ES cell commitment into cardiomyocytes and neurons ${ }^{[18]}$. Moreover, JNK MAPK phosphorylation has neuronal protective effects ${ }^{[19]}$. Thus, distinct mouse ES cell lineage commitment programs are likely regulated by the integrated action of multiple signaling mechanisms ${ }^{[20]}$. However, whether prenylflavonid compounds are prenylated by GGTase I catalysis and whether prenylflavonid compounds can in turn activate the MAPK signaling pathway associated with neuronal differentiation has not been reported. Here, we explore the protein prenylation effect of IBA and the subsequent MAPK pathway.

Our data demonstrated that IBA can promote neuronal differentiation from mouse ES cells. The mechanism involved protein prenylation and, subsequently, phos-ERK activation and the phos-P38/JNK off pathway.

\section{Materials and methods Materials}

IBA was prepared according to the existing protocol ${ }^{[21]}$. Retinoic acid (RA), dimethylsulfoxide (DMSO), 4,6-diamidino-2phenylindole (DAPI), and $\beta$-mercaptoethanol ( $\beta$-ME) were purchased from Sigma-Aldrich (St Louis, MO, USA). DMEM medium, neural basal medium, B27 supplement, fetal bovine serum (FBS) and GGTI-298 were obtained from Gibco BRL (Burlington, Ontario, Canada). Non-essential amino acid (NEAA) stock solution was purchased from Hyclon (Logan, UT, USA). Recombinant mouse leukemia inhibitory factor (LIF), primary antibodies against neural specific markers $\beta$-tubulin III, neurofilament (NEFM), and JNK were purchased from Chemicon (CA, USA). ERK (Cat \#9102) primary antibodies against GFAP, p38, phos-p38, phos-ERK, phos-JNK, and GAPDH were purchased from Cell Signaling. The HRP conjugated secondary antibodies (bovine anti-goat IgG-HRP, sc-2350, bovine anti-rabbit IgG-HRP, sc-2370, goat anti-mouse IgG-HRP, sc-2005) were purchased from Santa Cruz, Inc (CA, USA).

\section{Cell culture and differentiation scheme}

Mouse ES cells (D3 line, American Type Culture Collection, CRL-1934) ${ }^{[22]}$ were routinely cultured on primary cultured mouse embryonic fibroblasts (MEF) cells in DMEM, supplemented with $10 \%$ FBS, $0.1 \mathrm{mmol} / \mathrm{L} \beta$-mercaptoethanol ( $\beta$-ME), $1 \times \mathrm{NEAA}$ and $1 \times 10^{6} \mathrm{U} / \mathrm{L} \mathrm{LIF}^{[23]}$. The experiment conformed to the Guide for the Care and Use of Laboratory Animals published by the United States National Institutes of Health, and approval was granted by Ethics Review Board of Zhejiang University. A hanging drop method ${ }^{[24-26]}$ was used to initiate embryonic body (EB) formation in differentiation medium. A typical $4-/ 4+$ protocol was used to induce neuronal differentiation $^{[27]}$. Briefly, drops $(30 \mu \mathrm{L})$ containing approximately 900 ES cells were gently dropped on the lids of Petri dishes and were cultured for $2 \mathrm{~d}$ in hanging drops. After EB formation, they were transferred to agar-coated Petri dishes and cultured in suspension for another $2 \mathrm{~d}$. On d 4 , IBA $\left(10^{-7} \mathrm{~mol} / \mathrm{L}\right)$ was added to the medium, and EBs were cultured in suspension for another 4 d. As indicated, GGTase I inhibitor GGTI-298 $\left(10^{-6} \mathrm{~mol} / \mathrm{L}\right)$ was added into the medium with IBA during differentiation. On d 8+0, EBs were planted on poly-D-lysinecoated culture plates in differentiation medium (neural basal medium and 1\% B27 supplement) with IBA to induce neuronal differentiation. A culture treated with $10^{-7} \mathrm{~mol} / \mathrm{L}$ RA was used as a positive control, and 0.1\% DMSO was used as a solvent control.

\section{Morphological evaluation}

To evaluate the morphological changes during differentiation, an inverted microscope with a phase-contrast optic lens was used. Images were captured by a Leica DFC300 FX camera device, and the images were processed using Image-Pro Plus version 5.1 software (Media Cybernetics, MA, USA). Morphological evaluation was performed according to the existing protocol ${ }^{[28]}$ with some modification. The cells with axons at least three times longer than the size of their cell bodies were considered to be neuron-like cells.

\section{Immunocytochemistry analysis}

Immunostaining with cell markers was used to confirm the 
cell subtypes ${ }^{[29]}$. Cultures were washed with PBS solution and then fixed for $15 \mathrm{~min}$ in ice-cold methanol containing $0.3 \%$ hydrogen peroxide. Fixed cultures were then washed three times with PBS and incubated in blocking solution (10\% FBS in PBS) for $1 \mathrm{~h}$. After washing three times with PBS, the cultures were incubated with primary antibodies at a dilution of 1:50 in buffer $\left(0.5 \%\right.$ triton $\mathrm{X}-100$ in PBS) overnight at $4{ }^{\circ} \mathrm{C}$. Subsequently, the cultures were washed with PBS and incubated with the corresponding fluorescent secondary antibodies at a dilution of 1:200 for $2 \mathrm{~h}$, avoiding light. Then, the culture was incubated in $2 \mu \mathrm{g} / \mathrm{mL}$ DAPI solution in PBS for $1 \mathrm{~min}$ to label the nuclei. In the experiment, $\beta$-tubulin III was used as a neuron marker, and GFAP was used as an astrocyte marker. The immunostaining results were visualized by microscopic examination using a Leica inverted microscope equipped with a fluorescence system.

\section{Western blot analysis}

The cells were harvested and were lysed at $4{ }^{\circ} \mathrm{C}$ in extraction buffer containing Tris- $\mathrm{HCl}(\mathrm{pH} 7.5,20 \mathrm{mmol} / \mathrm{L}), \mathrm{NaCl}$ (150 mmol/L), EDTA (1 mmol/L), Triton X-100 (1\%), sodium deoxycholate $(0.5 \%)$, PMSF $(1 \mathrm{mmol} / \mathrm{L})$, leupeptin $(10 \mu \mathrm{g} / \mathrm{mL})$, and aprotinin $(30 \mu \mathrm{g} / \mathrm{mL})$. The lysates were centrifuged at $14000 \times g$ for $30 \mathrm{~min}$ at $4{ }^{\circ} \mathrm{C}$. The protein concentration was quantified by modified Lowry assay (DC protein assay; BioRad, Hercules, CA, USA). SDS-PAGE, Western blotting, and the optical density measurements of the films were performed according to existing protocols. Briefly, $40 \mu \mathrm{g}$ of protein was loaded on each lane, and the proteins were transferred to a nitrocellulose membrane after running SDS-PAGE. Transferred membranes were blocked for $1 \mathrm{~h}$ in $5 \%$ nonfat milk in Tris buffer containing $0.1 \%$ Tween-20 (TBS/T). The specific dilutions of the primary antibodies were as follows: NEFM (1:500); $\beta$-tubulin III (1:1000); GFAP (1:1000); p38 (1:500); phosp38 (1:500); ERK (1:1000); phos-ERK (1:500); JNK (1:500); phosJNK (1:500); and GAPDH (1:10000). Primary antibodies were diluted in $5 \%$ milk, and the blots were incubated overnight at $4{ }^{\circ} \mathrm{C}$. The blots were washed three times (15 min each) with $10 \mathrm{~mL}$ TBS/T and were incubated with secondary antibody
(1:5000) with gentle agitation for $1 \mathrm{~h}$ at room temperature. Then, the blots were washed three times with TBS/T and were exposed to a chemiluminescencent detection system using the Super Signal West Pico Substrate (Pierce, Rockford, IL, USA). Digital images of appropriate films were captured and quantified using the bio-imaging system (Bio-Rad, USA).

\section{Semi-quantitative RT-PCR analysis}

The total RNA was extracted with Trizol reagent according to the manufacturer's instructions. To synthesize first strand cDNA, $7 \mu \mathrm{L}$ total RNA was incubated with $0.5 \mu \mathrm{g}$ of oligo (dT) 6 primer and $5 \mu \mathrm{L}$ water at $65{ }^{\circ} \mathrm{C}$ for $15 \mathrm{~min}$. Reverse transcription reactions were performed using 200 units of M-MuLV reverse transcriptase (Gibco BRL) in $5 \times$ reaction buffer $\left(250 \mathrm{mmol} / \mathrm{L}\right.$ Tris-HCl; $\mathrm{pH} 8.3$ at $25^{\circ} \mathrm{C}, 375 \mathrm{mmol} / \mathrm{L} \mathrm{KCl}$, $15 \mathrm{mmol} / \mathrm{L} \mathrm{MgCl}_{2}, 50 \mathrm{mmol} / \mathrm{L}$ dithiothreitol) and $1 \mathrm{mmol} / \mathrm{L}$ dNTP (deoxynucleotide triphosphate) mixture containing $10 \times$ PCR buffer $\left(100 \mathrm{mmol} / \mathrm{L}\right.$ Tris- $\mathrm{HCl}$; pH 8.3 at $25^{\circ} \mathrm{C}, 500$ $\mathrm{mmol} / \mathrm{L} \mathrm{KCl}, 15 \mathrm{mmol} / \mathrm{L} \mathrm{MgCl}_{2}$ ), 25 units Taq polymerase (Sangon, China), $1 \mu \mathrm{L}$ of $10 \mathrm{mmol} / \mathrm{L}$ dNTP mixture, and 30 pmol of each primer. The final volume was adjusted to $50 \mu \mathrm{L}$. The PCR reactions were initiated by denaturation at $94{ }^{\circ} \mathrm{C}$, followed by annealing at a certain temperature (Table 1) for $45 \mathrm{~s}$ and amplification at $72{ }^{\circ} \mathrm{C}$ for $45 \mathrm{~s}$ using mastercycler gradient PCR amplifier (Eppendorf, Germany). The specific primer pairs and PCR reaction conditions are described in detail in Table 1.

The PCR products were analyzed by $1.5 \%$ agarose gel electrophoresis, visualized with ethidium bromide staining, and quantified by a bio-imaging analyzer (Bio-Rad, USA). The quantification analysis of the optical density of the products was performed using Quantity One software (Bio-Rad, USA).

\section{Results}

\section{Neuronal differentiation effect}

The morphological changes during the course of neuronal differentiation were observed. There was apparent difference between the IBA treatment group and the solvent control group. At the terminal of cultivation $d 8+10$ in our

Table 1. Primer sequences and reaction conditions for RT-PCR.

\begin{tabular}{|c|c|c|c|c|c|}
\hline Gene & Primer sequence & Size (bp) & $\begin{array}{c}\mathrm{Mg}^{2+} \\
\text { concentration } \\
(\mathrm{mmol} / \mathrm{L})\end{array}$ & $\begin{array}{c}\text { Annealing } \\
\text { temperature } \\
\operatorname{Tm}\left({ }^{\circ} \mathrm{C}\right)\end{array}$ & Cycle \\
\hline \multirow[t]{2}{*}{ GAPDH } & S: 5'-TGACGGGGTCACCCACACTGTGCCCATCTA-3' & 660 & 3 & 69 & 28 \\
\hline & A: 5'-CTAGAAGCATTTGCGGTGGACGATGGAGGG-3' & & & & \\
\hline \multirow[t]{2}{*}{$\beta$-tubulin III } & S: 5'-CTCCCTTCGATTCCCTGGTC-3' & 438 & 3 & 59 & 35 \\
\hline & A: 5'-TGCTCCGAGATGCGTTTGA-3' & & & & \\
\hline \multirow[t]{2}{*}{ GFAP } & S: 5'-GACTATCGCCGCCAACTGC-3' & 448 & 3 & 61 & 35 \\
\hline & A: 5'-CGCCTTGTGCTCCTGCTTC-3' & & & & \\
\hline \multirow[t]{2}{*}{ ОСТЗ/4 } & S: 5'-AGGGATGGCATACTGTGGAC-3' & 702 & 3 & 60 & 35 \\
\hline & A: 5'-CCTGGGAAAGGTGTCCTGTA-3' & & & & \\
\hline \multirow[t]{2}{*}{ Nestin } & S: 5'-CTGGGACTGAAGCACTGGG-3' & 384 & 3 & 59 & 35 \\
\hline & A: 5'-CGGACACCTCTTTGGGAAC-3' & & & & \\
\hline
\end{tabular}


study, RA $\left(10^{-7} \mathrm{~mol} / \mathrm{L}\right)$ and IBA $\left(10^{-7} \mathrm{~mol} / \mathrm{L}\right)$ significantly increased the population of neuron-like cells, which have axons more than three times longer than the length of their cell bodies $^{[9]}$ (Figure 2A). Neurons expressing $\beta$-tubulin III and astrocytes expressing GFAP induced by IBA were more obvious than those in solvent control (Figure 2B). The neural progenitor cell marker nestin is highly expressed in EBs (d 4 or $\mathrm{d} 8+0$ ) with or without IBA treatments, and expression decreases gradually during neuronal differentiation. Oct3/4, a marker of pluripotency, was highly expressed in ES cells and disappeared at terminal differentiation. The mRNA and protein levels of $\beta$-tubulin III were both expressed from the EB stage to terminal differentiation. However, only a small amount of GFAP was expressed at the early stage, and GFAP expression was up-regulated in a time-dependent manner (Figure 2C). NEFM, a neurofilament marker that can reveal the fates of axons, was up-regulated by IBA treatment (Figure 2D).

\section{Involvement of protein prenylation in IBA-promoted pneuronal differentiation}

GGTase I inhibitor GGTI-298 ${ }^{[11]}$ was used to explore whether protein prenylation was involved in neuronal differentiation of mouse ES cells in this study. After the treatment with IBA accompanied with $10^{-6} \mathrm{~mol} / \mathrm{L}$ GGTI-298 (no cytotoxicity to EBs, data not shown), the promoting effect in neuron and astrocyte differentiation was remarkably reduced as demonstrated by immunocytochemistry and Western blot analysis. Interestingly, GGTI-298 has no effect on RA-induced differentiation, which means that the promoting effects of IBA and RA on neuronal differentiation act via completely different pathways (Figure 3).

\section{Involvement of MAPK pathway in IBA promoted neuronal differentiation}

To explore the further possible mechanisms of the neuronal differentiation promoted by IBA, proteins related with the MAPK pathway were assessed by Western blot analysis. The samples were collected at multiple time points up to and including terminal differentiation. It was observed that p38 and JNK phosphorylation was detected during the ES and EB (d 4, d 8+0) passages and then was down-regulated on d $8+5$ and $d 8+10$. Moreover, little p38 phosphorylation was detected during the entire differentiation course. In contrast, ERK phosphorylation was detected in ES cells, little was seen in EBs $(\mathrm{d} \mathrm{4}, \mathrm{d} 8+0)$, and then it appeared to be up-regulated during the neuronal differentiation (Figure 4).

\section{Discussion}

Mouse ES cells as a model system can be used to investigate the effects of small molecules on differentiation and cell function in pharmacology ${ }^{[30]}$. Although numerous studies on the neuronal differentiation of mouse ES cells have been reported, the underlying molecular mechanism is probably a complex process and is still largely unknown. Recent studies have indicated that protein prenylation may play some role in the neu- ropharmacology of Alzheimer's disease ${ }^{[10]}$. Thus, we speculated that the process of protein prenylation may be associated with the neuronal differentiation induced by prenylflavonid compound IBA. IBA with prenyl group at position 8 of ring A may be activated by GGTase I, which can further regulate the ERK MAPK pathway and induce ES cell differentiation ${ }^{[11]}$. Moreover, mouse ES cell-derived neurons and astrocytes are regulated via the MAPK signaling pathway ${ }^{[11]}$. Pathways including ERK MAPK, and protein prenylation conceivably converge to alter the expression of cytoskeletal protein neurofilaments (NEFM) to modulate neurite outgrowth ${ }^{[31,32]}$ and promote neuronal differentiation from mouse ES cells. However, whether prenylflavonid compounds are capable of protein prenylation and other elements in the MAPK pathway are related to protein prenylation is still unknown.

In our study, at the early stages of the first two days in hanging drops and extra two days in suspension, mouse ES cells were allowed to form aggregated EBs, which resemble 5to 6-day-old mouse embryos in vivo ${ }^{[33]}$ and express the Oct3/4 gene. As shown in Figure 2, OCT3/4 was rapidly degraded following IBA treatment, while both $\beta$-tubulin III and GFAP were gradually expressed, representing neuron and astrocyte differentiation. Nestin, a well-known marker of neural progenitor cells in EBs, which was highly expressed in EBs (d 4, d $8+0$ culture), was remarkably down-regulated in the period of neuronal differentiation ( $\mathrm{d} 8+5, \mathrm{~d} 8+10$ culture) after IBA treatment, indicating that IBA can further promote neural progenitor cells to differentiate into terminal neuronal cells. More interestingly, a significantly increased number of neurons was observed in the IBA-treated cultures accompanied by astrocytes compared with solvent control.

IBA with a prenyl group at position 8 of ring A was found to possess neurogenesis stimulatory activity in our work, but whether prenylflavonoid compounds can play a role in protein prenylation in mouse ES cells and whether protein prenylation is necessary for neurogenesis has not yet been confirmed. To explore the possible role of protein prenylation in inducing neuronal differentiation, pure GGTase I inhibitor GGTI-298 was used. GGTI-298 co-treatment with IBA could obviously affect the fates of mouse ES-cell-derived neurons and astrocytes. Surprisingly, GGTI-298 co-treatment with RA had no effect on the differentiation of either neurons or astrocytes, suggesting that GGTI-298 has no effect on RA-induced neuronal cell generation. Therefore, GGTI-298 might block IBA-induced protein prenylation and influence the neuronal differentiation. These data demonstrate that a prenyl group at position 8 of ring A of IBA is capable of protein prenylation during neurogenesis of mouse ES cells. These effects make IBA and its derivatives promising candidates for developing an efficient method to derive more neuronal or neural progenitor cells for cell replacement therapy.

Protein prenylation has been reported to activate the ERK MAPK pathway ${ }^{[13,34]}$. It has also been reported that the sustained activation or phosphorylation of ERK is associated with differentiation ${ }^{[35]}$. In our study, the level of ERK phosphorylation was high in ES cells and was low in the early periods 
A
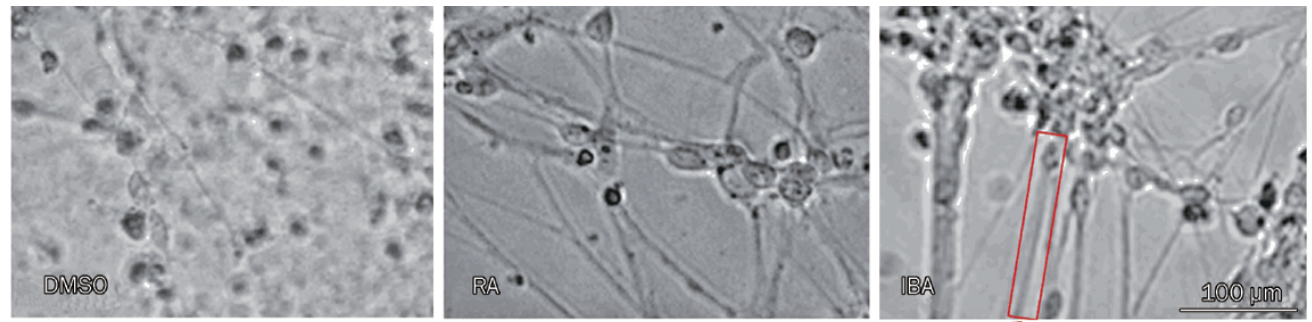

B
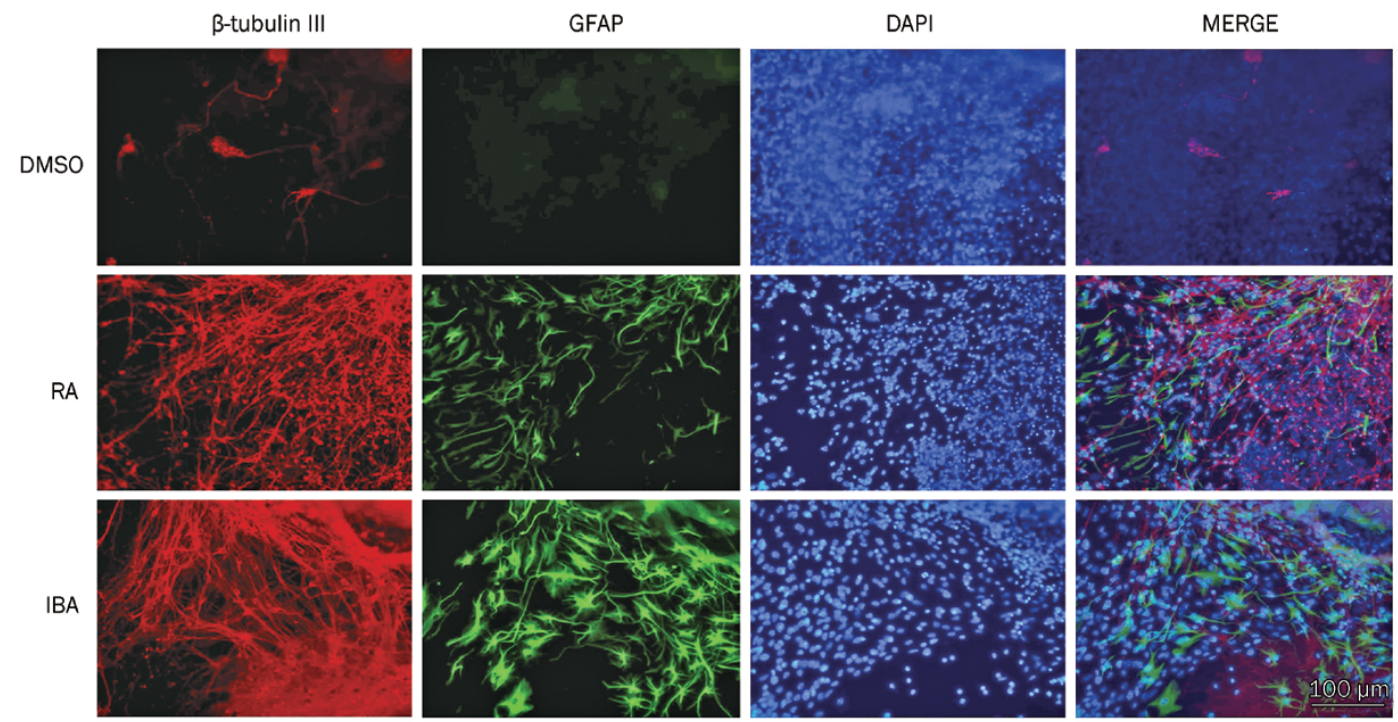

C
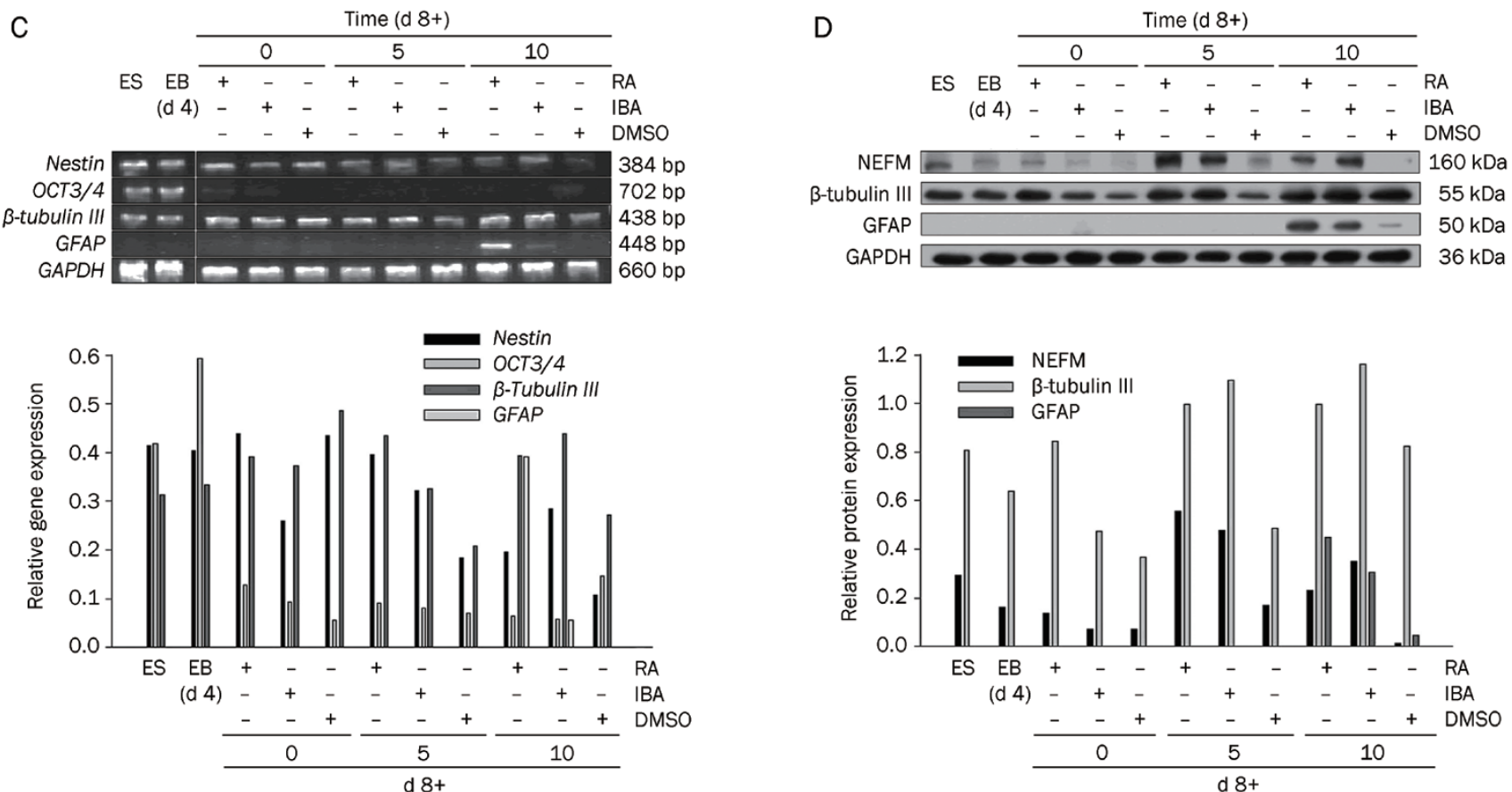

Figure 2. Differentiation potential of mouse ES cells into neurons and astrocytes after IBA treatment. All the morphological images were taken on d 8+10 EBs culture. DMSO: vehicle control; RA: $10^{-7} \mathrm{~mol} / \mathrm{L}$; IBA: $10^{-7} \mathrm{~mol} / \mathrm{L}$. (A) Morphological evaluation of neurongenesis of mouse ES cells induced by IBA. A typical axon with three times longer than the size of neuronal body (indicated with square) by phase contrast microscope. (B) Immunostaining with $\beta$-tubulin III (neuronal marker in red) or GFAP (astrocytes marker in green). DAPI staining (in blue) shows nuclear morphology. (C) RT-PCR analysis at different passages of mouse ES cells by IBA treatment. Stem cell marker gene (OCT3/4), neuronal genes (nestin for early differentiation, $\beta$-tubulin III and GFAP for late differentiation). The expression levels of genes were normalized with those of GAPDH gene. (D) Western blot analysis at different passages of mouse ES cells differentiation induced by IBA. $\beta$-tubulin III, NEFM for neurons, GFAP for astrocytes. The expression levels of proteins were normalized with those of GAPDH protein. 
A
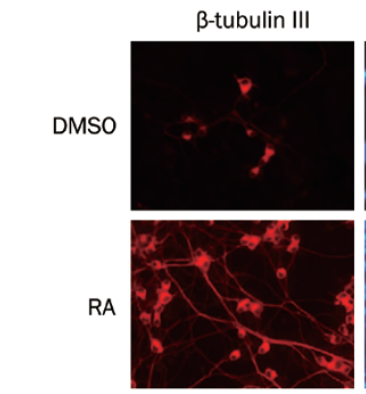

RA+

GGTI-298

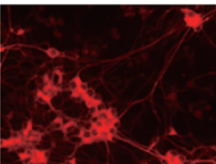

IBA

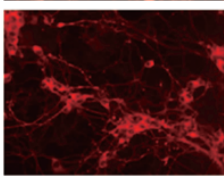

IBA+

GGTI-298

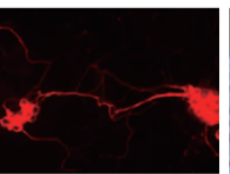

GGTI-298

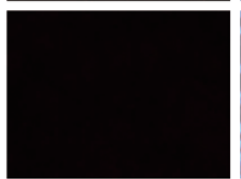

DAPI
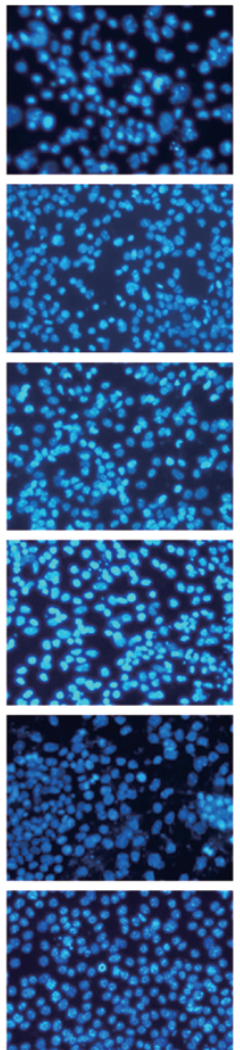

MERGE
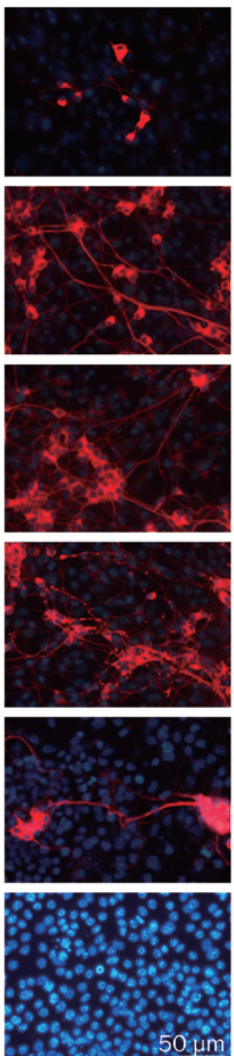

B
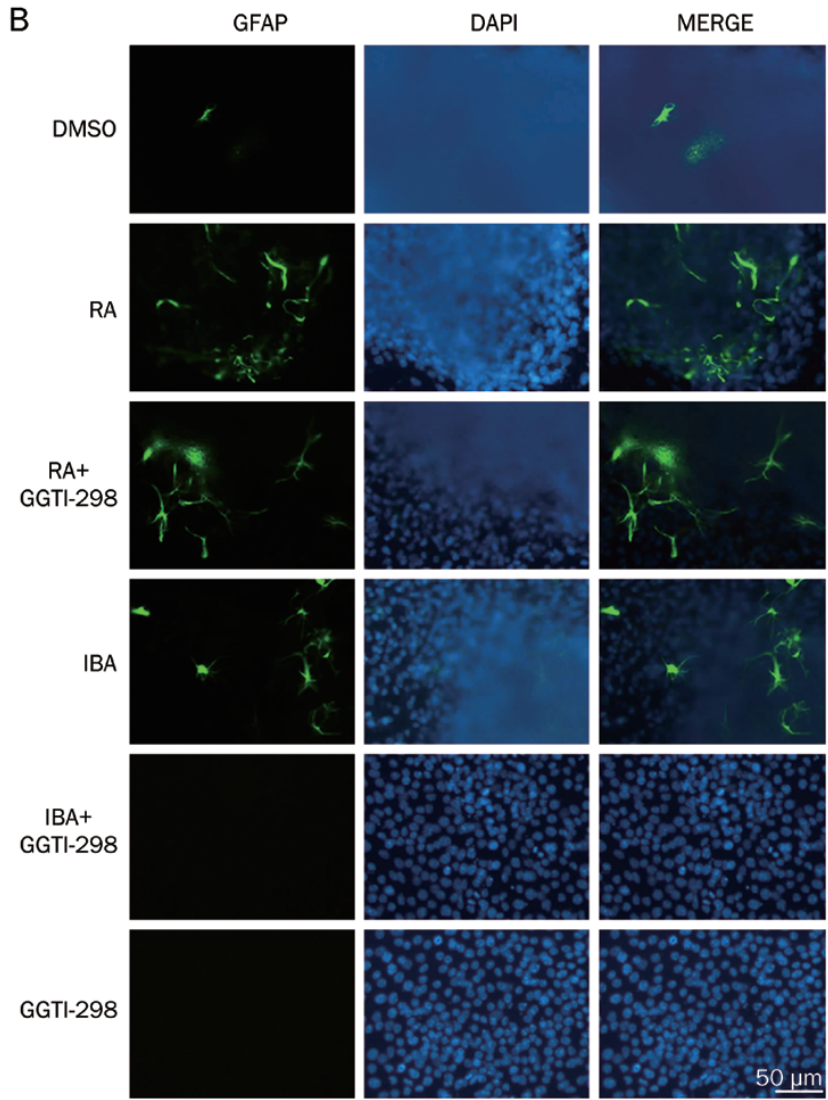

C
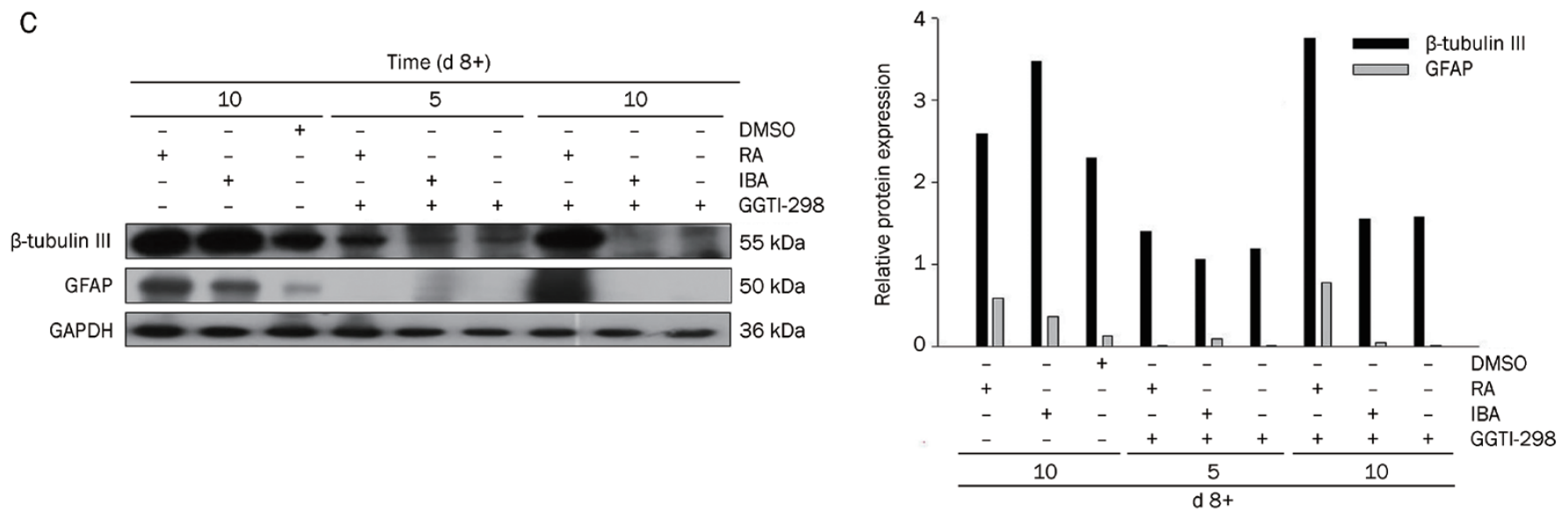

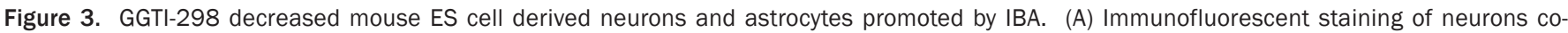

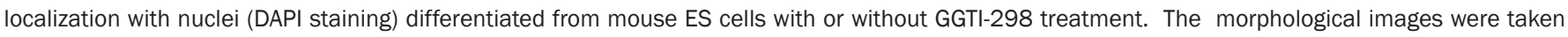

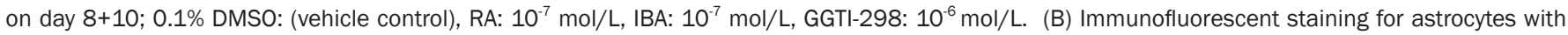

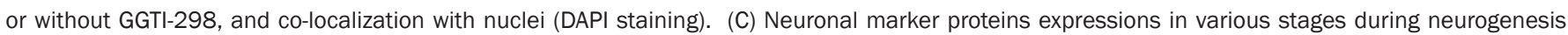

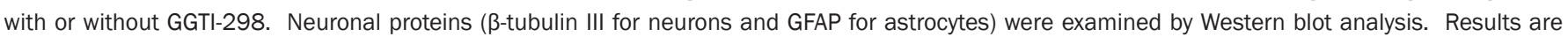
presented as the ratio of the target protein compared with GAPDH. The treatments were the same as (A).

of $\mathrm{d} 4$ and $\mathrm{d} 8+0$ EB culture, while it increased greatly during late neuronal differentiation at $\mathrm{d} 8+5$ and $\mathrm{d} 8+10$ culture. These data indicate that ERK phosphorylation is a key event required for the survival of ES cells and for neurite formation and neuron survival during mouse ES cell differentiation ${ }^{[16]}$. At $\mathrm{d} 4$ and $\mathrm{d} 8+0$ culture, nestin was highly expressed in EBs, while ERK phosphorylation was inhibited, suggesting that the inhibition of ERK phosphorylation is associated with neural 
A
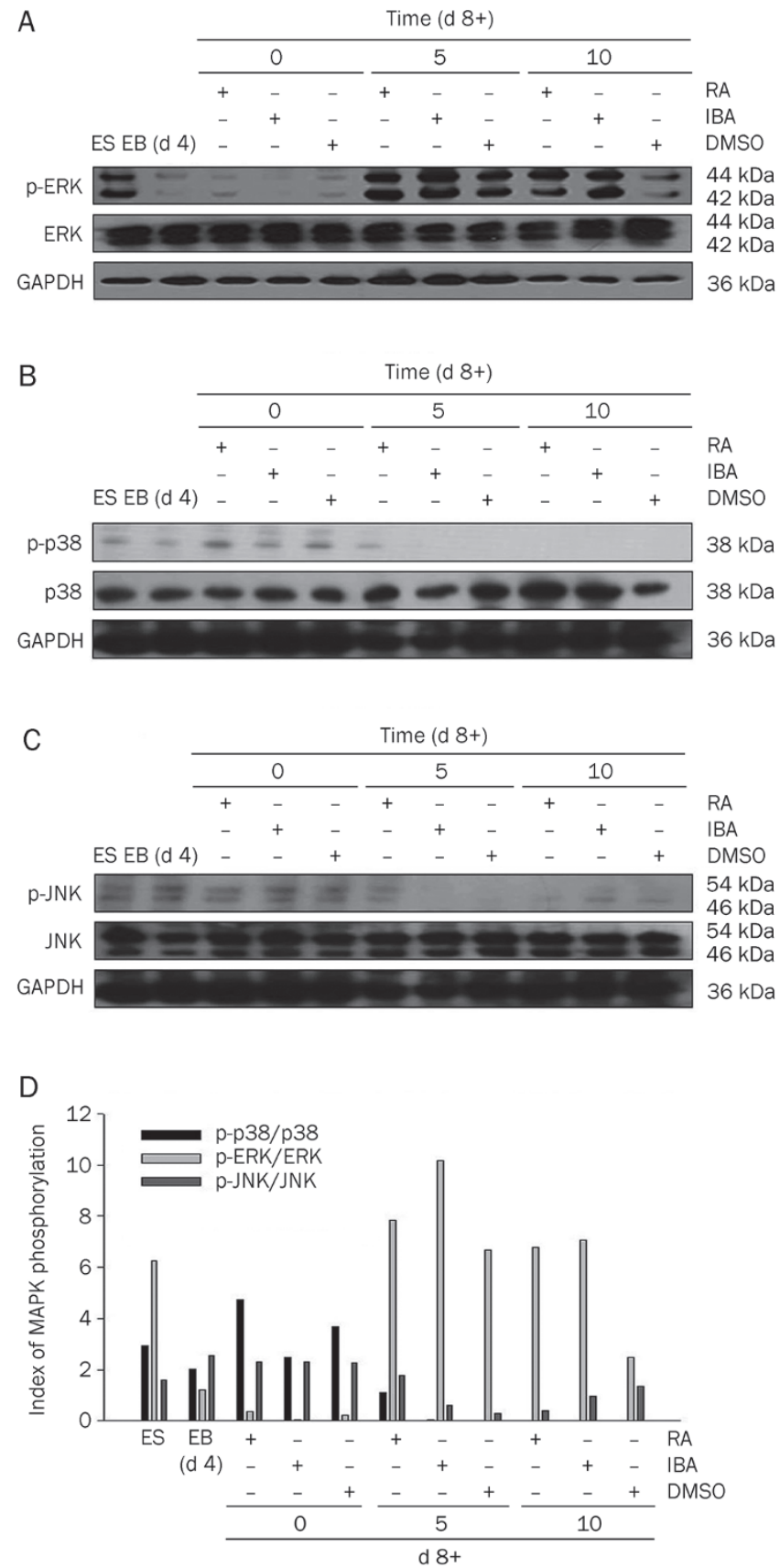

Figure 4. Effects of IBA on phosphorylation of MAPK pathway in ES cellsderive neurons and astrocytes by Western blot analysis. Samples were harvested at ES, EB, d 8+0, d 8+5, d 8+10 incubation with the treatment of various compounds. 0.1\% DMSO: (vehicle control); RA: $10^{-7} \mathrm{~mol} / \mathrm{L}$; IBA: $10^{-7} \mathrm{~mol} / \mathrm{L}$. (A) Phos-ERK; (B) phos-p38; (C) Phos-JNK; (D) The semi-quantified levels of phos-ERK, phos-JNK and phos-p38 ratio were represented by histograms.

progenitor formation in mouse ES cells. p38 MAPK phosphorylation was shown to be a trigger in determining whether ES cells differentiated into neuronal cells or cardiomyocytes ${ }^{[15]}$. The control of p38 MAPK activity constitutes an early switch in ES cell commitment into cardiomyocytes (phos-p38 on) and neurons (phos-p38 off) ${ }^{[18]}$. In our study, p38 phosphory- lation was expressed in the period of ES and EBs (d 4, d 8+0 culture), suggesting that p38 phosphorylation plays a critical role in maintaining mouse ES cell pluripotency and appears to promote neuroectoderm formation, while IBA can prevent p38 phosphorylation and subsequently promote neuronal differentiation. In the late period of neuronal differentiation, p38 phosphorylation was rare, indicating that p38 phosphorylation is associated with the trigger of mouse ES-cell differentiation and that its inhibition is important to neuronal differentiation. JNK phosphorylation was inhibited during neuronal differentiation compared with early stages of ES and EBs. It is noteworthy that the inhibitory effect of IBA on p38 is larger than on JNK phosphorylation. These results suggest that the regulation of the p38 and JNK MAPK signaling cascade may involve two mechanisms underlying the promoting effect of IBA on mouse ES cell neuronal differentiation ${ }^{[19]}$. Thus, a phosphatase-mediated crosstalk may exist between protein prenylation and the MAPK pathway in the regulation of neuronal differentiation from mouse ES cells promoted by IBA. Moreover, there may be a negative feedback regulation of their phosphorylation ${ }^{[17,36]}$. Otherwise, ERK, p38, and JNK may be downstream targets of protein prenylation. However, how IBA regulates the ERK/JNK/p38 MAPK pathways and the specific relationship with protein prenylation needs to be further investigated.

In conclusion, this study suggests that IBA (prenyl group at position 8 of ring A) can facilitate the differentiation of mouse ES cells into multiple kinds of neuronal cell subtypes, such as neurons and astrocytes. The mechanism involved protein prenylation and, subsequently, phos-ERK activation and the phos-p38 off pathway.

\section{Acknowledgements}

This work was supported by the National Natural Science Foundation of China (NSFC № 30973600, № 90813026).

\section{Author contribution}

Yi-jia LOU: Conception and design, financial support, final approval of manuscript; Dan-yin WANG: Provision of study material, acquisition of data and data analysis, manuscript writing; Yu-zhe HU and Si-si KONG: Partial acquisition of data; Yong-ping YU: Partial provision of study molecule; Danyan ZHU: Partial conception and new skills; all authors have read and approved the final manuscript.

\section{References}

1 MacLaren RE, Pearson RA. Stem cell therapy and the retina. Eye (Lond) 2007; 21: 1352-9.

2 Xing F, Fang Z, Qin B, Li Y, Hou J, Chen X. Parthenogenetic embryonic stem cells derived from cryopreserved newborn mouse ovaries: a new approach to autologous stem cell therapy. Fertil Steril 2009; 91: 1238-44.

3 Emre N, Coleman R, Ding S. A chemical approach to stem cell biology. Curr Opin Chem Biol 2007; 11: 252-8.

4 Trompouki E, Zon LI. Small molecule screen in zebrafish and HSC expansion. Methods Mol Biol 2010; 636: 301-16.

$5 \mathrm{Xu}$ Y, Shi Y, Ding S. A chemical approach to stem-cell biology and 
regenerative medicine. Nature 2008; 453: 338-44.

6 Dantuma E, Merchant S, Sugaya K. Stem cells for the treatment of neurodegenerative diseases. Stem Cell Res Ther 2010; 1: 37.

7 Ding S, Schultz PG. Small molecules and future regenerative medicine. Curr Top Med Chem 2005; 5: 383-95.

8 Tavakoli-Nezhad M, Arbogast LA. Mu and kappa opioid receptor expression in the mediobasal hypothalamus and effectiveness of selective antagonists on prolactin release during lactation. Neuroscience 2010; 166: 359-67.

9 Wang Z, Wang H, Wu J, Zhu D, Zhang X, Ou L, et al. Enhanced coexpression of beta-tubulin III and choline acetyltransferase in neurons from mouse embryonic stem cells promoted by icaritin in an estrogen receptor-independent manner. Chem Biol Interact 2009; 179: 37585.

10 Ochocki JD, Igbavboa U, Gibson Wood W, Wattenberg EV, Distefano MD. Enlarging the scope of cell-penetrating prenylated peptides to include farnesylated 'CAAX' box sequences and diverse cell types. Chem Biol Drug Des 2010; 76: 107-15.

11 Chen S, Fu L, Raja SM, Yue P, Khuri FR, Sun SY. Dissecting the roles of DR4, DR5 and C-FLIP in the regulation of geranylgeranyltransferase I inhibition-mediated augmentation of TRAIL-induced apoptosis. Mol Cancer 2010; 9: 23.

12 Seabra MC. Membrane association and targeting of prenylated Raslike GTPases. Cell Signal 1998; 10: 167-72.

13 Kim HS, Kim JW, Gang J, Wen J, Koh SS, Koh JS, et al. The farnesyltransferase inhibitor, LB42708, inhibits growth and induces apoptosis irreversibly in H-ras and K-ras-transformed rat intestinal epithelial cells. Toxicol Appl Pharmacol 2006; 215: 317-29.

14 Binetruy B, Heasley L, Bost F, Caron L, Aouadi M. Concise review: regulation of embryonic stem cell lineage commitment by mitogenactivated protein kinases. Stem Cells 2007; 25: 1090-5.

15 Roux PP, Blenis J. ERK and p38 MAPK-activated protein kinases: a family of protein kinases with diverse biological functions. Microbiol Mol Biol Rev 2004; 68: 320-44.

$16 \mathrm{Li}$ Z, Theus MH, Wei L. Role of ERK $1 / 2$ signaling in neuronal differentiation of cultured embryonic stem cells. Dev Growth Differ 2006; 48: 513-23.

17 Wang Z, Yang $\mathrm{H}$, Tachado SD, Capo-Aponte JE, Bildin VN, Koziel H, et al. Phosphatase-mediated crosstalk control of ERK and p38 MAPK signaling in corneal epithelial cells. Invest Ophthalmol Vis Sci 2006; 47: 5267-75.

18 Aouadi M, Bost F, Caron L, Laurent K, Le Marchand Brustel Y, Binetruy B. p38 mitogen-activated protein kinase activity commits embryonic stem cells to either neurogenesis or cardiomyogenesis. Stem Cells 2006; 24: 1399-406.

19 Zeng KW, Fu H, Liu GX, Wang XM. Icariin attenuates lipopolysaccharide-induced microglial activation and resultant death of neurons by inhibiting TAK1/IKK/NF-kappaB and JNK/p38 MAPK pathways. Int Immunopharmacol 2010; 10: 668-78.

20 Rajan P, McKay RD. Multiple routes to astrocytic differentiation in the
CNS. J Neurosci 1998; 18: 3620-9.

$21 \mathrm{Liu}$ J, Ye H, Lou Y. Determination of rat urinary metabolites of icariin in vivo and estrogenic activities of its metabolites on MCF-7 cells. Pharmazie 2005; 60: 120-5.

22 Doetschman TC, Eistetter H, Katz M, Schmidt W, Kemler R. The in vitro development of blastocyst-derived embryonic stem cell lines: formation of visceral yolk sac, blood islands and myocardium. J Embryol Exp Morphol 1985; 87: 27-45.

23 Stewart R, Stojkovic M, Lako M. Mechanisms of self-renewal in human embryonic stem cells. Eur J Cancer 2006; 42: 1257-72.

24 Zhu DY, Lou YJ. Inducible effects of icariin, icaritin, and desmethylicaritin on directional differentiation of embryonic stem cells into cardiomyocytes in vitro. Acta Pharmacol Sin 2005; 26: 477-85.

25 Metzger JM, Lin WI, Johnston RA, Westfall MV, Samuelson LC. Myosin heavy chain expression in contracting myocytes isolated during embryonic stem cell cardiogenesis. Circ Res 1995; 76: 710-9.

26 Scholz G, Pohl I, Genschow E, Klemm M, Spielmann H. Embryotoxicity screening using embryonic stem cells in vitro: correlation to in vivo teratogenicity. Cells Tissues Organs 1999; 165: 203-11.

27 Bain G, Kitchens D, Yao M, Huettner JE, Gottlieb DI. Embryonic stem cells express neuronal properties in vitro. Dev Biol 1995; 168: $342-$ 57.

28 Murashov AK, Pak ES, Hendricks WA, Tatko LM. 17beta-Estradiol enhances neuronal differentiation of mouse embryonic stem cells. FEBS Lett 2004; 569: 165-8.

29 Zhang SC, Wernig M, Duncan ID, Brustle O, Thomson JA. In vitro differentiation of transplantable neural precursors from human embryonic stem cells. Nat Biotechnol 2001; 19: 1129-33.

30 Wobus AM. Potential of embryonic stem cells. Mol Aspects Med 2001; 22: 149-64.

31 Canals M, Angulo E, Casado V, Canela El, Mallol J, Vinals F, et al. Molecular mechanisms involved in the adenosine $A$ and $A$ receptorinduced neuronal differentiation in neuroblastoma cells and striatal primary cultures. J Neurochem 2005; 92: 337-48.

32 Li BS, Zhang L, Gu J, Amin ND, Pant HC. Integrin alpha(1) beta(1)mediated activation of cyclin-dependent kinase 5 activity is involved in neurite outgrowth and human neurofilament protein $\mathrm{H}$ Lys-Ser-Pro tail domain phosphorylation. J Neurosci 2000; 20: 6055-62.

33 Martin GR, Evans MJ. Differentiation of clonal lines of teratocarcinoma cells: formation of embryoid bodies in vitro. Proc Natl Acad Sci U S A 1975; 72: 1441-5.

34 Solomon CS, Goalstone ML. Dominant negative alpha-subunit of FTase inhibits effects of insulin and IGF-I in MCF-7 cells. Biochem Biophys Res Commun 2002; 291: 458-65.

35 Marshall CJ. Specificity of receptor tyrosine kinase signaling: transient versus sustained extracellular signal-regulated kinase activation. Cell 1995; 80: 179-85.

36 Estrada Y, Dong J, Ossowski L. Positive crosstalk between ERK and p38 in melanoma stimulates migration and in vivo proliferation. Pigment Cell Melanoma Res 2009; 22: 66-76. 